\title{
Intramural cysts of the ileum
}

\author{
C. D. COLlinS, L. LOW, AND A. C. HUNT
}

From Bristol Royal Infirmary

SUMMARY A case of intramural cysts of the ileum is described for the first time. The clinical presentation and pathological findings are presented and the possible aetiology is discussed.

Mucous cysts are known to occur in the wall of the colon and the rectum, and since Goodall and Sinclair (1957) described the first two cases which were not associated with either chronic dysentery or tuberculosis, the condition has usually been referred to as colitis cystica profunda. Cystic lesions in relation to the small intestine are less common, and usually are in the form of extramural enterocoeles originating from embryonic remnants or reduplications. The condition described in this paper has features similar to some of the reported instances of colitis cystica profunda (Epstein, Ascari, Ablow, Seaman, and Lattes, 1966; Ghani, 1970), but because there is no evidence of any inflammatory origin we prefer to use the name 'intramural cysts of the ileum' rather than ileitis cystica profunda. This condition has not previously been described.

\section{Case Report}

A stoical 42-year-old coal merchant was admitted to the Bristol Royal Infirmary with intense colicky abdominal pain and vomiting of 18 hours' duration. On examination he was a well built, muscular man suffering pain severe enough to make him roll round in agony. He was dehydrated, the abdomen was slightly distended and tender, and the bowel sounds were increased. Plain radiographs of the abdomen revealed several fluid levels suggesting lower small bowel obstruction.

For 10 years he had suffered similar attacks of colicky pains relieved by vomiting which on one occasion had been described as faeculent by his medical practitioner. He also gave a history of vague upper abdominal dyspepsia, investigation of which revealed a hiatus hernia but no evidence of peptic ulcer or gallbladder disease.

The patient was rehydrated and submitted to exploratory laparotomy. This revealed dilated small

Received for publication 3 August 1971. bowel down to what at first appeared to be a short intussusception of the ileum $35 \mathrm{~cm}$ proximal to the ileo-caecal valve. The bowel formed a saccular dilatation distal to a short annular thickening of the wall (Fig. 1). The rest of the ileum proximal to the lesion appeared dilated, thickened, somewhat

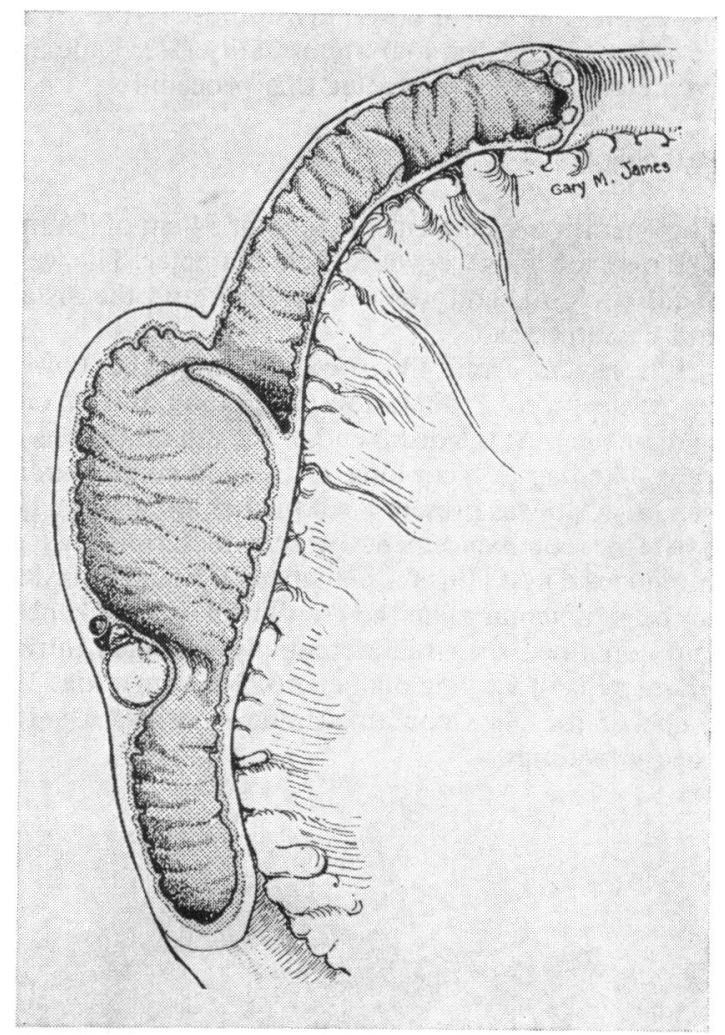

Fig. 1 Illustration of specimen of ileum removed at operation to show the two rows of cysts and the valvelike flaps. 
injected, and the mesentery attached to it was thickened up to $3 \mathrm{~cm}$ in places and contained enlarged fleshy lymph nodes. The distal ileum was collapsed and appeared normal. A diagnosis of probable Crohn's disease was made so the intestine was resected well clear of the abnormal area and anastamosed end to end. There was no other visible or palpable intraabdominal abnormality.

Postoperatively the patient at first recovered well from his abdominal operation, but he developed troublesome supraspinatus tendinitis which responded to local corticosteroid injections. Two months later he returned with a palpable tender mass in the right iliac fossa which was diagnosed as an intraabdominal abscess, possibly of appendicular origin. This settled completely on antibiotics. He was submitted to elective appendicectomy eight months later at which time an appendix was removed which was normal both macroscopically and microscopically. It was noted, however, that the mesentery was still greatly thickened and that there was evidence of an abscess which had resolved in relation to the previous small bowel anastamosis. There was no other intraabdominal abnormality. He made an uninterrupted recovery after this procedure.

\section{Pathology}

The operation specimen consisted of $54 \mathrm{~cm}$ of ileum. The resected ends were each $7 \mathrm{~cm}$ diameter. The wall at the proximal end was $0.4 \mathrm{~cm}$ thick and the distal end $0.2 \mathrm{~cm}$ thick.

Fifteen $\mathrm{cm}$ from the proximal end, the bowel formed a saccular dilatation $(9 \mathrm{~cm}$ long and $12 \mathrm{~cm}$ in diameter). At the distal end of the dilatation was a valve-like flap ( $2.5 \mathrm{~cm}$ long). A second similar rudimentary flap was present $8 \mathrm{~cm}$ further along (Fig. 1).

At the commencement of the dilatation was a submucosal cyst $(1.6 \mathrm{~cm}$ in diameter). Four $\mathrm{cm}$ distal to the rudimentary flap the bowel wall was thickened and contained six circumferentially arranged intramural cysts of varying diameter $(0 \cdot 3-1 \cdot 5 \mathrm{~cm})$ (Fig. 2). Some of the cysts contained mucus, others a soft, cheesy material.

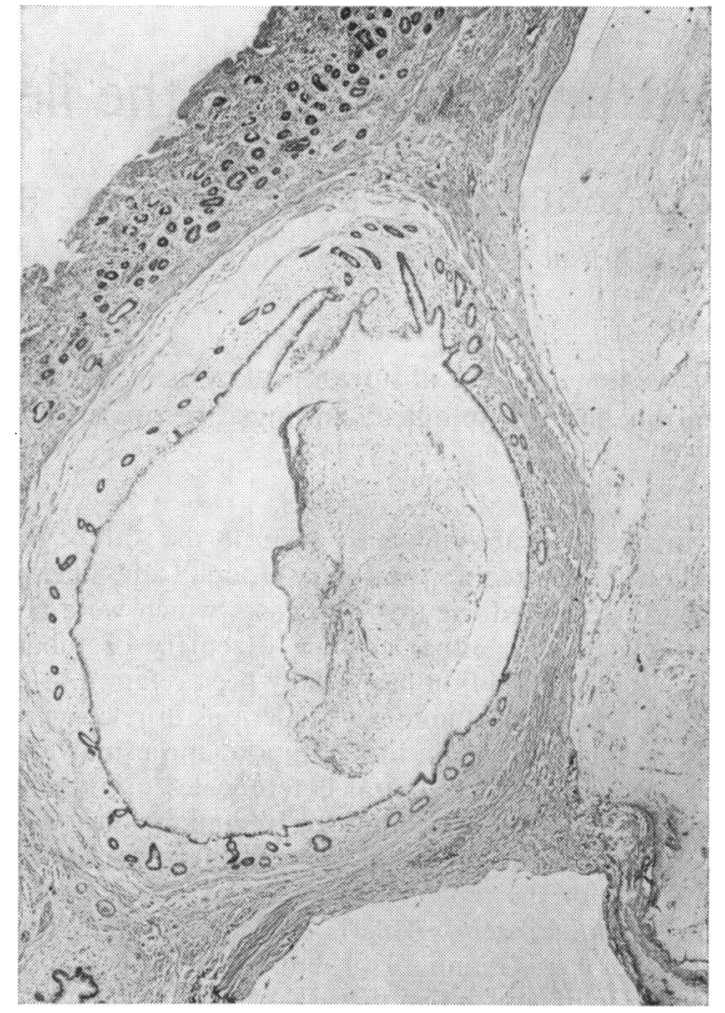

Fig. 3 Section showing one small epithelium-lined cyst and the edges of two large cysts. $H \& E \times 20$.

\section{Microscopy}

The valve consisted of an invagination of two complete layers of bowel wall. The mucosa appeared normal and was continuous with the bowel mucosa.

Random sections of the ileum showed no abnormality apart from hypertrophy of the muscularis in the sections from the proximal end. The mesentery showed marked lymphatic oedema, but no inflam-

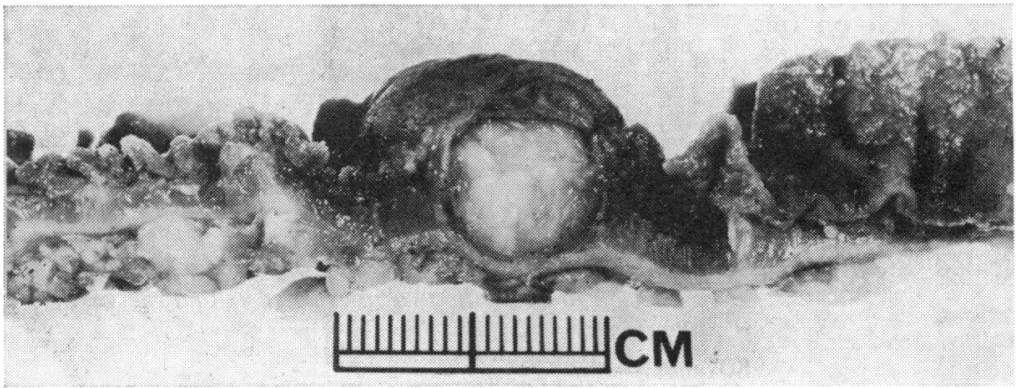

Fig. 2 Macroscopic appearance of one of the intramural ileal cysts. 
matory cell infiltrate and no abnormality in the enlarged oedematous lymph nodes.

The cysts were embedded in the muscularis (Fig. 3) which was in places compressed and thinned on either side of them. They contained mucin and amorphous eosinophilic debris, and in some there were extensive calcium deposits in the contents. The mucin in a few cysts was laminated circumferentially. The large cysts were lined by flattened fibrous tissue and there was no trace of any epithelium.

In addition to the large cysts, several smaller cysts were revealed by microscopy. These were lined with a simple mucus-secreting columnar epithelium surrounded by a loose lamina propia, but with no muscularis mucosae.

No inflammatory changes were present in relation to the cysts or elsewhere in the specimen. One of the cysts connected with the lumen of the ileum by an epithelium-lined tract passing through the muscularis mucosae.

\section{Discussion}

With the exception of Crohn's disease, pathological abnormalities of the small intestine are rarely found on routine preoperative investigation. They usually present surgically only when complications occur. The role of the cysts in the aetiology of this patient's intestinal obstruction can only be conjectured. It may be that the saccular segment of bowel developed as a post-stenotic dilatation distal to the proximal ring of cysts and that the valvular fold appeared secondarily. Alternatively the intermittent subacute intestinal obstruction from which the patient suffered for 10 years may have been caused by the valve-like spur of tissue projecting into the ileal lumen. The most probable explanation is that the spur is of congenital origin as are the cysts which lie in close proximity to it. It seems likely that all the cysts at one time had a mucus-secreting lining which has since disappeared from the larger cysts by a process of pressure atrophy.

The pathological appearances are very similar to the localized form of colitis cystica (Wayte and Helwig, 1967). This has been suggested to be of congenital origin, but the finding of occasional communications between the cysts and the intestinal lumen has prompted some workers (eg, Ghani, 1970) to support the hypothesis that they are due to pressure herniation. In our case, cysts were found distal to the site of obstruction, so it is unlikely that they are secondary to it. The massive lymphatic oedema of the mesentery is similar to that described in the first case of Goodall and Sinclair. No satisfactory explanation can be offered for this, but it is of interest to note that in one of the dogs in which Poppe (1941) produced experimental lymphatic blockage, there were epithelial changes not unlike those of colitis cystica profunda, although no such lesion was induced in the ileum. That underlying lymphatic obstruction may be the cause and not the effect of the intramural cysts of the ileum reported here is suggested by the persistence of the oedema 10 months after removal of the abnormal segment of bowel.

I would like to thank Mr W. K. Eltringham under whose care this patient was admitted to hospital, and Mr Gary James whose artistic representation of the operative specimen clarifies the appearance of the different lesions.

\section{References}

Epstein, S. E., Ascari, W. Q., Ablow, R. C., Seaman, W. B., and Lattes, R. (1966). Colitis cystica profunda. Amer. J. clin. Path., 45, 186-201.

Ghani, A. (1970). Colitis cystica profunda. Brit. J. Surg., 57, 596-598. Goodall, H. B., and Sinclair, I. S. R. (1957). Colitis cystica profunda. J. Path. Bact., 73, 33-42.

Poppe, J. K. (1941). Reproduction of ulcerative colitis in dogs. Arch. Surg., 43, 551-558.

Wayte, D. M., and Helwig, E. B. (1967). Colitis cystica profunda. Amer. J. clin. Path., 48, 159-169. 